\title{
Vortex-assisted ionic liquid-based dispersive liquid-liquid micro-extraction and spectrofluorometric determination of Rhodamine $B$ in anti-freeze, lipstick, liquid soap, matches and red pencil core \\ Abdullah Taner BIşGín ${ }^{1 *}$
}

\begin{abstract}
A simple, centrifugeless vortex-assisted ionic liquid-based dispersive liquid-liquid microextraction method was developed for spectrofluorometric determination of Rhodamine B dye. Analytical extraction parameters including $\mathrm{pH}$, type and amount of ionic liquid, salt concentration, vortex rate and time were examined and optimized. Matrix effects of potentially interfering ions and dyes were investigated and their tolerable concentrations were determined by applying optimum conditions. Detection limit and preconcentration factor were determined $0.01 \mu \mathrm{g} \mathrm{L}^{-1}$ and 30, respectively. Dynamic range of the method was linear at $\mathrm{RhB}$ concentration range between 0.025 and $1000 \mu \mathrm{g} \mathrm{L}^{-1}$. Relative standard deviations were $3.9 \%$ for the ten replicates measurements of $0.125 \mu \mathrm{g} \mathrm{L}^{-1}$ Rhodamine B. The method was successfully applied to different samples including anti-freezes, liquid soap, matches, red pencil core and lipsticks. RhB concentrations of liquid and solid samples were determined between $2.05 \mu \mathrm{g} \mathrm{mL}^{-1}$ and $10.05 \mu \mathrm{g} \mathrm{mL}^{-1}$ and $307 \mu \mathrm{g} \mathrm{g}^{-1}$ and $2.75 \mathrm{mg} \mathrm{g}^{-1}$, respectively.
\end{abstract}

Keywords: Dispersive liquid-liquid micro-extraction, ionic liquid, rhodamine B, spectrofluorometry

\footnotetext{
Abdullah Taner BỉşGíN (Orcid ID: 0000-0002-3557-3090), Niğde Ömer Halisdemir Üniversitesi, Ulukışla Meslek Yüksekokulu, Niğde, Türkiye

*Sorumlu Yazar/Corresponding Author: Abdullah Taner BİŞGİN, e-mail: atbisgin@ohu.edu.tr

Bu çalışmanın bir kısmı 1-4 Mayıs 2019 tarihlerinde Didim/AYDIN'da düzenlenen ' 4 th International Conference on New Trends in Chemometrics and Applications’ isimli konferansta sözlü sunum olarak sunulmuştur.
}

Geliş tarihi / Received: 13-03-2020

Kabul tarihi / Accepted: 01-05-2020 


\section{INTRODUCTION}

Rhodamine $\mathrm{B}(\mathrm{RhB})$ is highly water soluble xanthene organic dye containing aromatic benzene rings. Although it has been banned to use in food and different products, it has been still used illegally in cosmetic, food, textile and industrial samples due to its low cost, stability and high effectiveness in dying process (Chen et al., 2014). RhB is harmful if swallowed and inhaled by human and animals. It damages to human skin and eyes if in direct contact (Ranjbari and Hadjmohammadi, 2015). Its toxicity, carcinogenicity, neurotoxicity and chronic toxicity towards human and animals have been proved (Alesso et al., 2012; Qi et al., 2014). For these reasons, detection and determination of $\mathrm{RhB}$ in different available products are important and essential.

Therefore, scientists in the world, especially analytical chemists have studied to determine RhB contents of commercially available products by using instrumental analytical techniques and devices including liquid chromatography-mass spectrometry (LC-MS) (Li et al., 2013; Cheng and Tsai, 2016), ultra violet-visible spectrophotometry (Unsal et al., 2014a; Unsal et al., 2014b), spectrofluorometry (Fu et al., 2015; Roostaie et al., 2017), electrochemical methods (Sun and Yang, 2017) and high performance liquid chromatography (HPLC) (Tatebe et al., 2014; Xu et al., 2016). Although chromatographic methods supply sensitive quantitative determination, it could not be available in many laboratories because the instrument price is considerably high and it has needed highly skilled and experienced operators (Bişgin, 2018; Li et al., 2020). Due to their simplicity and lower cost than other instruments, UV-visible spectrophotometry and spectrofluorometry are the attractive techniques (Bişgin, 2019a). However, these techniques have not ensured satisfactory results due to necessity for pretreatments of complicated sample matrix and the insufficient sensitivity (Liang et al., 2015). Therefore, it is very important to develop a sensitive, simple, cost-effective and rapid method for the determination of Rhodamine B (Liu et al., 2013).

Particularly, spectrofluorometry is low-cost, simple, rapid and highly sensitive. It has been widely used for direct determination of fluorescence dye like $\mathrm{RhB}$. Unfortunately, complex matrix interference and low concentration of $\mathrm{RhB}$ limit the direct determination of $\mathrm{RhB}$ contents in sample. Therefore, it has great importance to apply at least one or more pretreatment process prior to the determination of trace target analyte RhB in complicated samples (Bakheet and Zhu, 2017).

In order to isolate the $\mathrm{RhB}$ from complex matrix sample, different separation, enrichment and purification methods including solid-phase extraction (SPE) (Su et al., 2015; Yan et al., 2017), cloud point extraction (CPE) (Ghasemi and Kaykhaii, 2016; Bişgin et al., 2018), deep eutectic solvent extraction (DES) (Wang et al., 2017; Yilmaz and Soylak, 2018) and dispersive liquid-liquid micro-extraction (DLLME) (Unsal et al., 2014a; Bağda and Tuzen, 2017) have been used and reported. DLLME method is interesting because of its simplicity, considerably high preconcentration factor, rapid and effective phase separation. In addition, this method uses only very little amounts of toxic organic solvents (Bişgin, 2019b). Therefore, chemists have developed new methods with using surfactants, ultrasonic bath, vortex and ionic liquids based on DLLME method. These are surfactant assisted dispersive liquid-liquid micro extraction (SA-DLLME) (Sadeghi et al., 2018), ultrasound assisted dispersive liquid-liquid micro extraction (UA-DLLME) (Altunay et al., 2019), vortex assisted dispersive liquid-liquid micro extraction (VA-DLLME) (Elik et al., 2017) for extraction of trace substances.

Aim of this study was to develop a VA-IL-DLLME method for extraction and spectrofluorometric determination of RhB. For this purpose, ionic liquid 1-butyl-3-methylimidazolium hexafluorophosphate 
$\left[\mathrm{C}_{4} \mathrm{MIM}\right]\left[\mathrm{PF}_{6}\right]$ and vortex were used. Several analytical parameters, affecting recovery results, were investigated and optimized. The optimized method was applied to anti-freezes, lipsticks, liquid soap, matches and red pencil core samples to determine their RhB contents. Finally, analytical characteristics and performance of the method were evaluated and compared with reported studies.

\section{MATERIALS AND METHOD}

\section{Chemicals}

Analytical grade chemicals were used in the experiments and purchased from Merck (Merck, Darmstadt, Germany) and Sigma (Sigma-Aldrich, St. Louis, MO, USA). In the preparation of buffer solutions $\mathrm{H}_{3} \mathrm{PO}_{4}-\mathrm{NaH}_{2} \mathrm{PO}_{4}$ for $\mathrm{pH} 2$ and $\mathrm{pH} 3, \mathrm{HAc}-\mathrm{NaAc}$ for $\mathrm{pH} 4$ and $\mathrm{pH} 5$ and $\mathrm{NaH}_{2} \mathrm{PO}_{4}-\mathrm{Na}_{2} \mathrm{HPO}_{4}$ for $\mathrm{pH} 6, \mathrm{pH} 7$ and $\mathrm{pH} 8$ were used.

$100 \mu \mathrm{g} \mathrm{mL} \mathrm{m}^{-1}$ of $\mathrm{RhB}$ stock dye solution was prepared and stored in refrigerator at $4{ }^{\circ} \mathrm{C}$. More diluted dye solutions were prepared daily from the $\mathrm{RhB}$ stock dye solution. The chemical structure of $\mathrm{RhB}$ is given in Figure 1a.

$\mathrm{NaCl}, \mathrm{KCl}$ and $\mathrm{Na}_{2} \mathrm{SO}_{4}$ were used as model electrolytes in the extraction experiments. Extensively used dyes and common metal ions (Table 1) were used to prepare model matrix solutions.

1-butyl-3-methylimidazolium hexafluorophosphate $\left[\mathrm{C}_{4} \mathrm{MIM}\right]\left[\mathrm{PF}_{6}\right]$ as an ionic liquid, was used to extract $\mathrm{RhB}$ dye molecules from aqueous phase to organic phase. The chemical structure of $\left[\mathrm{C}_{4} \mathrm{MIM}\right]\left[\mathrm{PF}_{6}\right]$ is given in Figure 1b. Pure ethanol was used for solving and diluting the bulk ionic liquid rich phase.
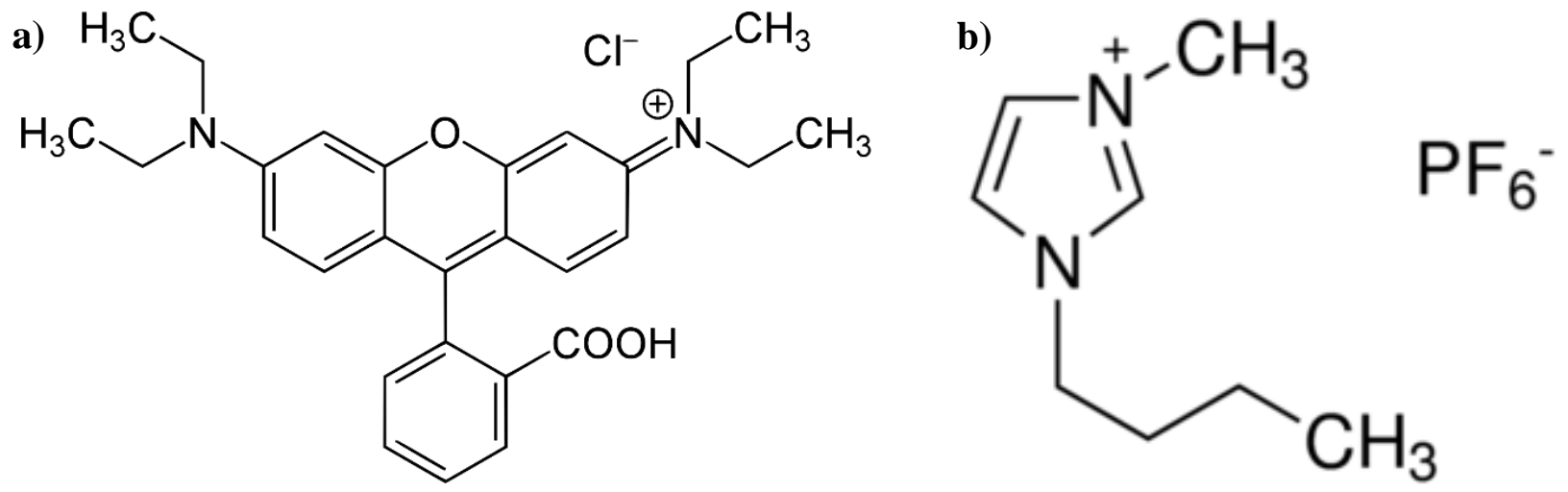

Figure 1. The chemical structures of $\mathrm{RhB}(\mathrm{a})$ and $\left[\mathrm{C}_{4} \mathrm{MIM}\right]\left[\mathrm{PF}_{6}\right]$ (b)

\section{Instruments}

RhB emission measurements were performed by using Hitachi F-7100 fluorescence spectrophotometer (Hitachi, Tokyo, Japan). $\mathrm{pH}$ adjustments of aqueous and buffer solutions were performed with using a digital pH-meter (Hanna Instruments, USA). A Velp ZX3 model advanced vortex mixer (Velp Scientifica, Italy) was used for vortexing aqueous mixture. A double-beam Shimadzu UV-160 A (Shimadzu Corporation, Kyoto, Japan) UV-Vis Spectrophotometer was used to determine UV-Vis spectra of the real samples.

\section{VA-IL-DLLME Procedure}

Fifteen milliliters of sample solution containing $0.250 \mu \mathrm{g}$ of $\mathrm{RhB}$ and $0.3 \mathrm{~mol} \mathrm{~L}^{-1}$ of $\mathrm{KCl}$ was buffered to $\mathrm{pH}$ 2.5. The solution was decanted to centrifuge tube. $240 \mu \mathrm{L}$ of $\left[\mathrm{C}_{4} \mathrm{MIM}\right]\left[\mathrm{PF}_{6}\right]$ was added to solution. 
The mixture containing two clear phases was vortexed for 60 seconds at $2400 \mathrm{rpm}$. Organic fine droplets containing $\mathrm{RhB}$ molecules were collected bottom of the centrifuge tube after vortex process. Aqueous upper phase was removed by a syringe. Analyte rich phase was diluted to $500 \mu \mathrm{L}$ of final volume with ethanol. $\mathrm{RhB}$ dye was excited at $520 \mathrm{~nm}$ of excitation wavelength and measured at $576 \mathrm{~nm}$ of emission wavelength.

\section{Pretreatment of real samples}

Anti-freeze samples: $1.0 \mathrm{~mL}$ of each anti-freeze samples were directly subjected to optimized method after $\mathrm{pH}$ adjustments.

Lipstick Samples: $\mathrm{RhB}$ amounts of each of $25 \mathrm{mg}$ lipstick samples were dissolved with $\mathrm{CCl}_{4}$. $\mathrm{RhB}$ molecules in the organic phase were extracted to water phase by $25 \mathrm{~mL}$ of $0.1 \mathrm{~mol} \mathrm{~L}^{-1} \mathrm{NaOH}$ with using a separatory funnel. $5 \mathrm{~mL}$ of extract was applied to method after $\mathrm{pH}$ adjustments.

Liquid soap: An amount of $10.0 \mathrm{~g}(8 \mathrm{~mL})$ liquid soap sample was dried in an oven at $50{ }^{\circ} \mathrm{C}$. Dried sample was dissolved in water and diluted to $2.0 \mathrm{~mL}$. The solution was analyzed with applying the developed method after filtering through blue band filter paper and adjusting $\mathrm{pH}$.

Red pencil core: An amount of $12.5 \mathrm{mg}$ red pencil core was accurately weighed. Then it was dissolved in pure water and subsequently filtered through blue band filter paper. The filtrate was diluted to $25 \mathrm{~mL}$ in a volumetric flask. Then $1.0 \mathrm{~mL}$ of the solution was applied to the developed method after $\mathrm{pH}$ adjustments.

Matches: Matches samples were weighed $(10 \mathrm{mg})$ and dissolved in pure water. Then, samples were filtered through blue band filter paper and solution was diluted to $25 \mathrm{~mL}$ with distilled water. $1.0 \mathrm{~mL}$ of solution was subjected to the developed method after $\mathrm{pH}$ adjustments.

\section{RESULTS AND DISCUSSION}

UV-Vis, fluorescence excitation and fluorescence emission data for the determination of $\mathrm{RhB}$ dye in anti-freeze, red pencil core, matches, pure aqueous solution, lipstick and liquid soap samples are given in Fig. 2, Fig. 3 and Fig. 4, respectively.

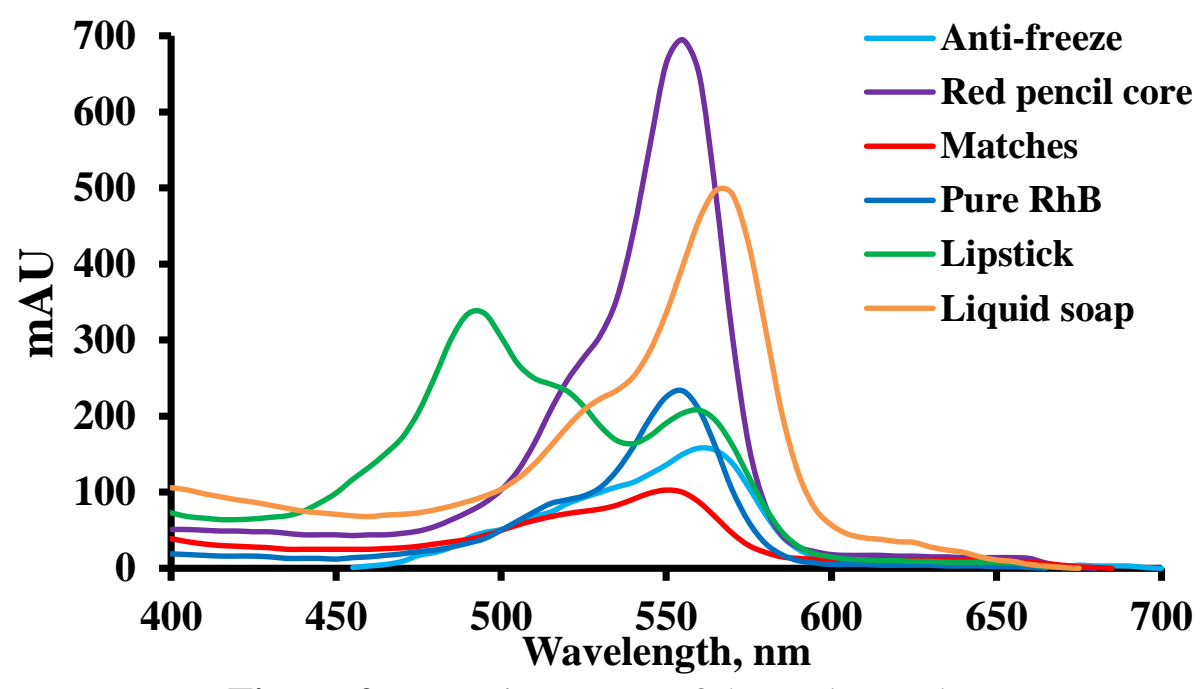

Figure 2. UV-Vis spectra of the real samples 


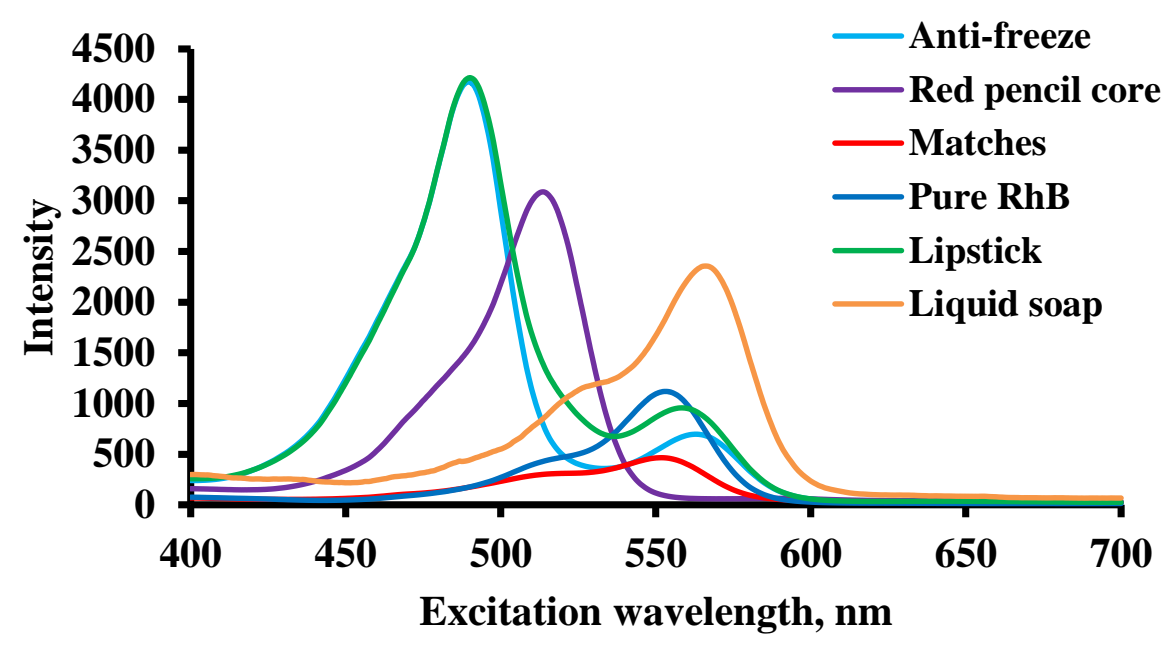

Figure 3. Fluorescence excitation spectra of the real samples

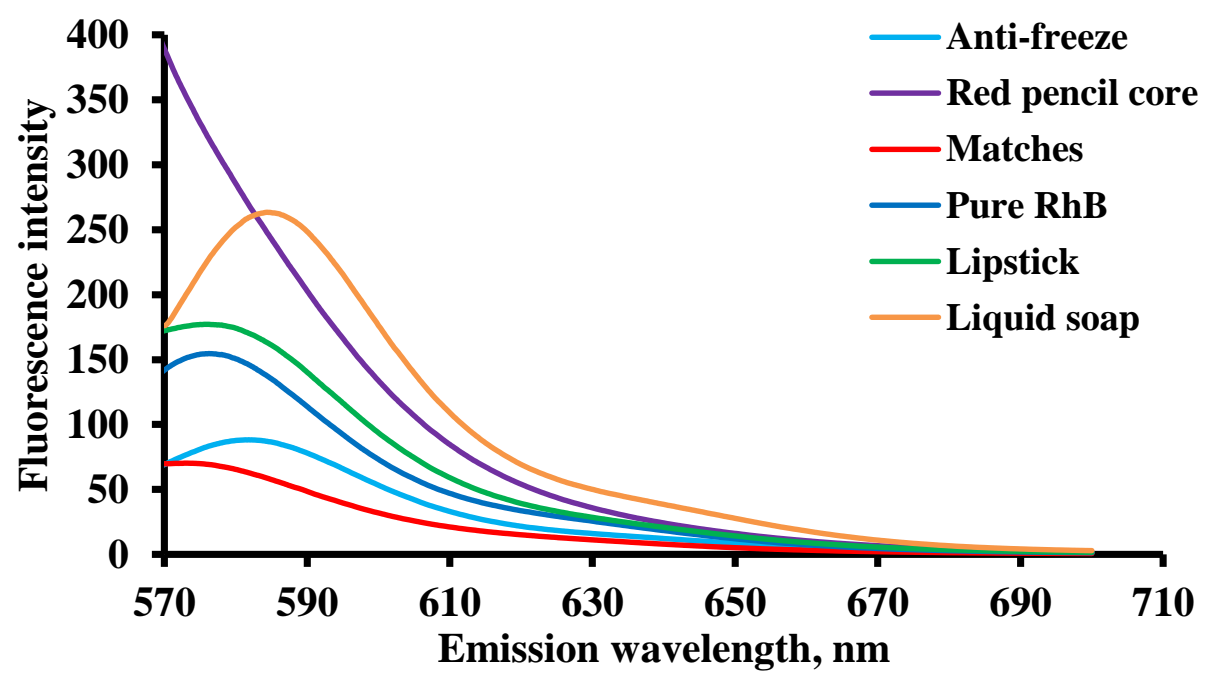

Figure 4. Fluorescence emission spectra of the real samples

\section{Influence of $\mathbf{p H}$}

Aqueous media $\mathrm{pH}$ is important for $\mathrm{pH}$ sensitive and dependent dye such as $\mathrm{RhB}$. The influences of $\mathrm{pH}$ on the extractions of $\mathrm{RhB}$ molecules into ionic liquid organic phase were investigated between $\mathrm{pH} 2$ and pH 8 by using $15 \mathrm{~mL}$ of model solutions containing $0.250 \mu \mathrm{g} \mathrm{RhB}$. The results are presented in Fig. 5 with standard deviations. Quantitative extractions of $\mathrm{RhB}$ were observed in the $\mathrm{pH}$ range of 2-3. In acidic media, $\mathrm{RhB}$ molecules were surrounded by ionic liquid molecules. Thus, RhB dye was quantitatively $(>95 \%)$ extracted from large aqueous phase into small ionic liquid phase. At higher $\mathrm{pH}$ values, the cationic form of $\mathrm{RhB}$ molecules turned into to the neutral one and its recovery value decreased. Similar results were observed in literature value (Soylak et al., 2011). Therefore, all subsequent studies were performed at $\mathrm{pH} 2.5$ by using $\mathrm{H}_{3} \mathrm{PO}_{4} / / \mathrm{NaH}_{2} \mathrm{PO}_{4}$ buffer. 


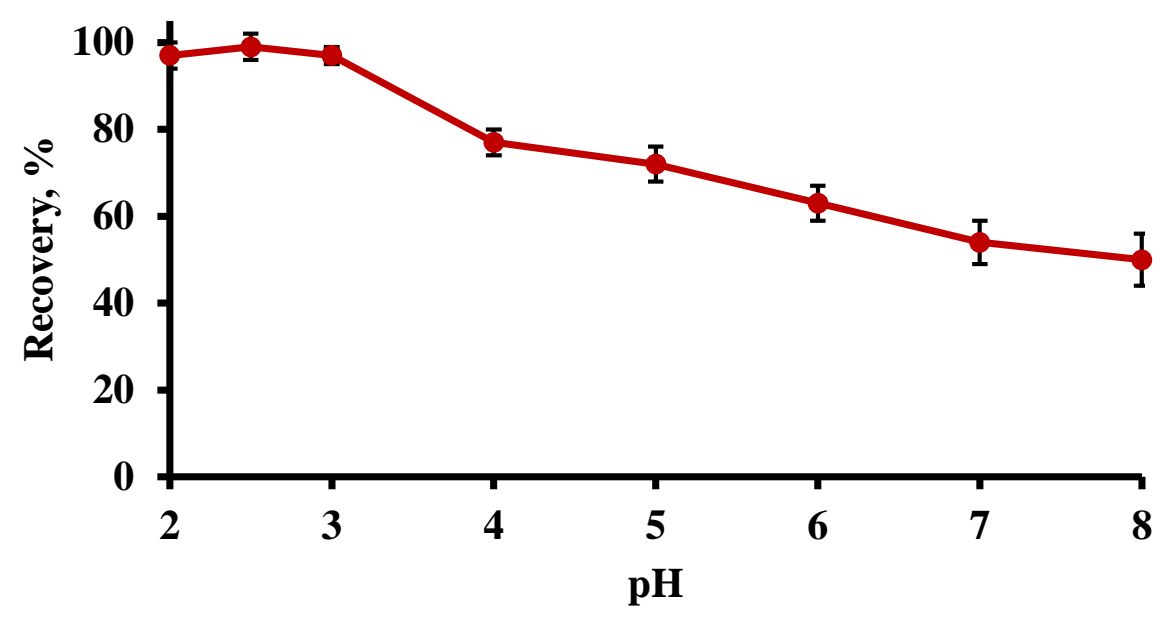

Figure 5. Influence of $\mathrm{pH}, \mathrm{N}=4$

\section{Effect of ionic liquid amount}

Ionic liquid amount is important parameter for complete extraction of $\mathrm{RhB}$ molecules from aqueous phase to IL rich phase. In order to extract $\mathrm{RhB}$ dye, $\left[\mathrm{C}_{4} \mathrm{MIM}\right]\left[\mathrm{PF}_{6}\right]$ and $\left[\mathrm{C}_{4} \mathrm{MIM}\right]\left[\mathrm{BF}_{4}\right]$ ionic liquids were used. In presence of $\left[\mathrm{C}_{4} \mathrm{MIM}\right]\left[\mathrm{BF}_{4}\right]$ extraction was not performed because blurred solution formed and phase separation was not obtained. Therefore, $\left[\mathrm{C}_{4} \mathrm{MIM}\right]\left[\mathrm{PF}_{6}\right]$ was selected and then used in all further extraction studies. IL volume was examined between 60-270 $\mu \mathrm{L}$. Results are depicted in Fig. 6 with standard deviations. Recovery values increased with increasing IL amount up to $210 \mu \mathrm{L}$ and then remained constant. Quantitative extraction was obtained between 210 and $270 \mu \mathrm{L}$. Hence, $240 \mu \mathrm{L}$ of $\left[\mathrm{C}_{4} \mathrm{MIM}\right]\left[\mathrm{PF}_{6}\right]$ was chosen optimum amount for further studies.

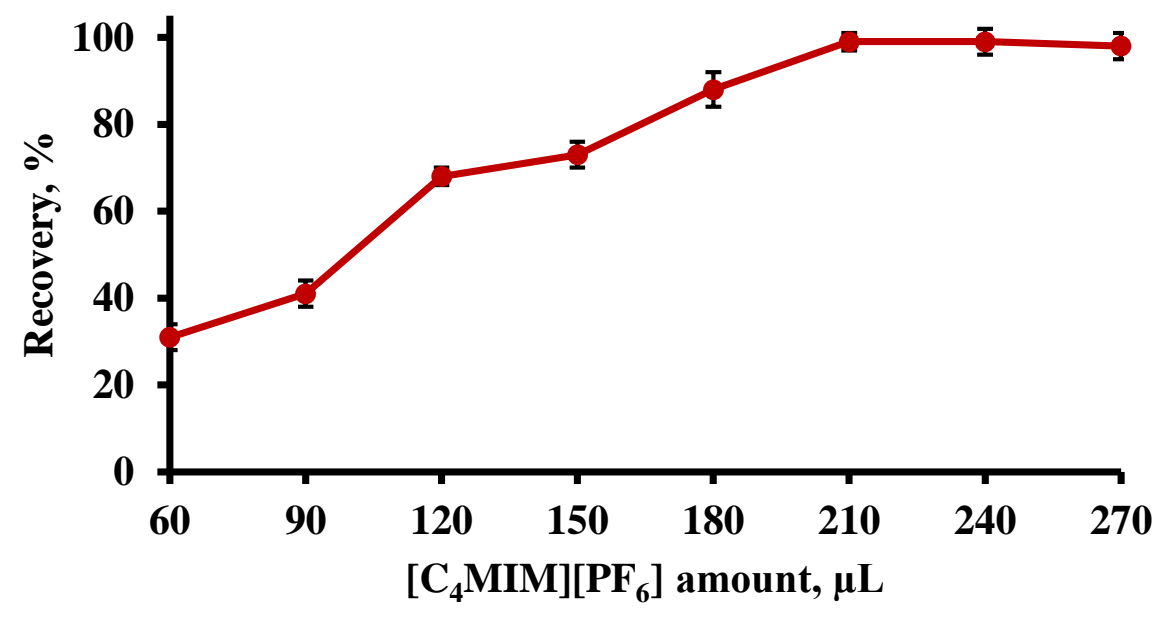

Figure 6. Effect of $\left[\mathrm{C}_{4} \mathrm{MIM}\right]\left[\mathrm{PF}_{6}\right]$ amount, $\mathrm{N}=4$

\section{Effect of salt concentration}

Extraction efficiency usually increases with increasing ionic strength of aqueous solution because of salting out effect (Chen and $\mathrm{Zhu}, 2016$ ). The effect of ionic strength was evaluated by using $\mathrm{NaCl}, \mathrm{KCl}$ and $\mathrm{Na}_{2} \mathrm{SO}_{4}$ as model electrolytes on the extraction efficiency. In presence of $\mathrm{KCl}$, stabile, repeatable and the quantitative extraction value was obtained. Therefore, $\mathrm{KCl}$ was selected for subsequent experiments. Salt 
concentration was examined a concentration range of $0-0.04 \mathrm{~mol} \mathrm{~L}^{-1}$. results are given in Fig. 7 with standard deviations. Over this concentration interval, the cloudy solution was formed. RhB recoveries increased with increasing $\mathrm{KCl}$ concentration up to $0.2 \mathrm{~mol} \mathrm{~L}^{-1}$ and remain stable above this value. Therefore, $0.3 \mathrm{~mol} \mathrm{~L}^{-1}$ of $\mathrm{KCl}$ concentration was applied in all further experimental studies.

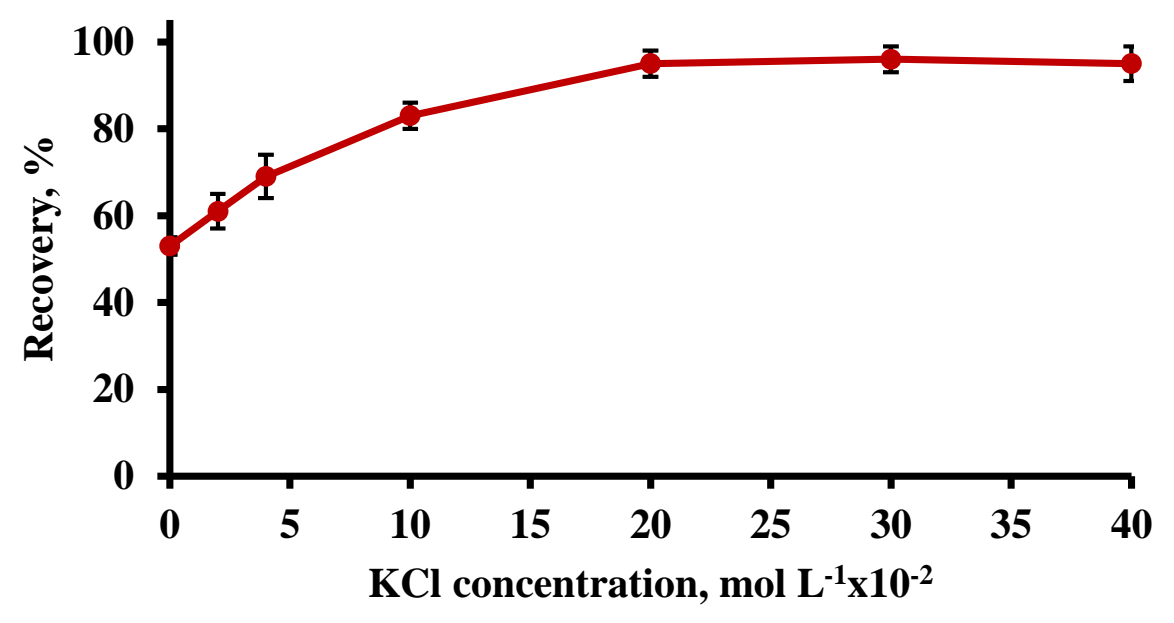

Figure 7. Effect of $\mathrm{KCl}$ concentration, $\mathrm{N}=4$

\section{Influence of vortex time}

Optimization of vortex time is necessary to achieve equilibrium and entire dispersion of IL in aqueous phase by resulting in complete extraction of $\mathrm{RhB}$ molecules from aqueous phase to IL droplets. Optimized enough vortex time is the minimum time to obtain equilibrium between aqueous and IL rich phase by ensuring higher extraction efficiency (Bağda and Tuzen, 2017). Vortex time was investigated at $2400 \mathrm{rpm}$ between 10 and 80 seconds. $2400 \mathrm{rpm}$ was selected an optimum because enough agitation was not achieved below than this value. Results are presented in Fig. 8 with standard deviations. Recoveries increased with increasing vortex time. Quantitative extraction and sufficient formation of ionic droplets were obtained only after 50 seconds. Therefore, 60 seconds vortexing at $2400 \mathrm{rpm}$ was chosen optimum for further experimental studies.

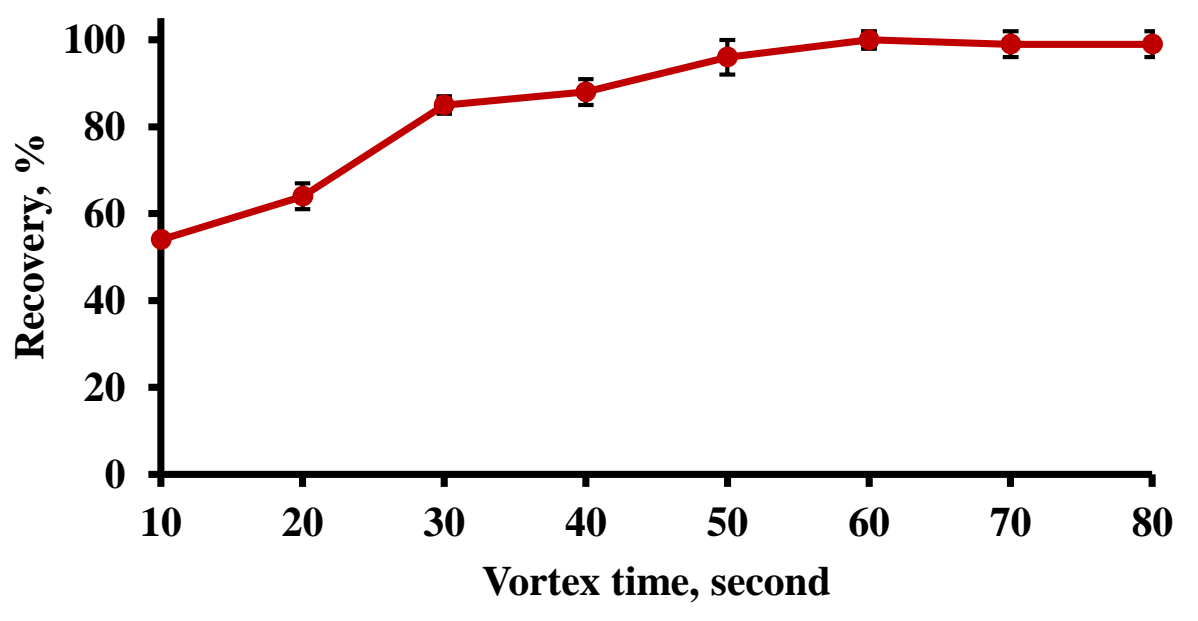

Figure 8. Influence of vortex time, $\mathrm{N}=4$ 


\section{Effect of matrix}

It is necessary that effect of matrix components on the trace determination of analyte should be examined in detection and determination process. Interference effects of matrix components including widely used dyes, potentially available anions and cations were also examined. Results are given in Table 1 with standard deviations. Dyes and ions at concentrations levels, which are given in Table 1, did not interfere the analysis at the optimized conditions of the method. At the optimum conditions of the developed method, ionic liquid $\left[\mathrm{C}_{4} \mathrm{MIM}\right]\left[\mathrm{PF}_{6}\right]$ extracted only $\mathrm{RhB}$ molecules as quantitative from aqueous sample solution in presence of other matrix dyes given in Table 1. This circumstance has provided the selectivity to the proposed method. In addition, fluorescence determination provided selectivity to the developed method because RhB has the fluorescence characteristic among other matrix dyes, which are given in Table 1. The used dyes in matrix study have not fluorescence characteristics therefore, any emission wavelengths, which could be interfered the fluorescence determination, were not observed by fluorescence excitation with using fluorescence spectrometer. Thus, only RhB molecules were determined applying both excitation and emission wavelength. In addition, differences between excitation and emission wavelength of RhB increased the selectivity. Moreover, excitation wavelengths and emission wavelengths are specific for each dye that has fluorescence characteristic.

Table 1. Matrix effect of the potentially interfering components, $\mathrm{N}=4$

\begin{tabular}{|c|c|c|c|}
\hline Dyes or ions & Added species & Concentration, $\mu \mathrm{g} \mathrm{mL}^{-1}$ & Recovery, \% \\
\hline Tartrazine & - & 4 & a99 \pm 2 \\
\hline Sunset yellow & - & 3 & $98 \pm 3$ \\
\hline Brilliant blue & - & 4 & $97 \pm 3$ \\
\hline Ponceau 4R & - & 1 & $97 \pm 4$ \\
\hline Allura red & - & 1 & $100 \pm 1$ \\
\hline $\mathrm{Co}^{2+}$ & $\mathrm{Co}\left(\mathrm{NO}_{3}\right)_{2} \cdot 6 \mathrm{H}_{2} \mathrm{O}$ & 100 & $99 \pm 2$ \\
\hline $\mathrm{Ni}^{2+}$ & $\mathrm{Ni}\left(\mathrm{NO}_{3}\right)_{2} \cdot 6 \mathrm{H}_{2} \mathrm{O}$ & 100 & $98 \pm 3$ \\
\hline $\mathrm{Na}^{+}$ & $\mathrm{NaNO}_{3}$ & 1000 & $97 \pm 4$ \\
\hline $\mathrm{Mg}^{2+}$ & $\mathrm{Mg}\left(\mathrm{NO}_{3}\right)_{2} \cdot 6 \mathrm{H}_{2} \mathrm{O}$ & 1000 & $96 \pm 2$ \\
\hline $\mathrm{Cu}^{2+}$ & $\mathrm{Cu}\left(\mathrm{NO}_{3}\right)_{2} .5 \mathrm{H}_{2} \mathrm{O}$ & 100 & $98 \pm 1$ \\
\hline $\mathrm{Cr}^{3+}$ & $\mathrm{Cr}\left(\mathrm{NO}_{3}\right)_{3} .3 \mathrm{H}_{2} \mathrm{O}$ & 25 & $99 \pm 4$ \\
\hline $\mathrm{Cd}^{2+}$ & $\mathrm{Cd}\left(\mathrm{NO}_{3}\right)_{2} \cdot 6 \mathrm{H}_{2} \mathrm{O}$ & 100 & $99 \pm 2$ \\
\hline $\mathrm{K}^{+}$ & $\mathrm{KNO}_{3}$ & 1000 & $98 \pm 3$ \\
\hline $\mathrm{Mn}^{2+}$ & $\mathrm{Mn}\left(\mathrm{NO}_{3}\right)_{2} \cdot 4 \mathrm{H}_{2} \mathrm{O}$ & 100 & $97 \pm 3$ \\
\hline $\mathrm{Ca}^{2+}$ & $\mathrm{CaCl}_{2}$ & 1000 & $96 \pm 4$ \\
\hline $\mathrm{Pb}^{2+}$ & $\mathrm{Pb}\left(\mathrm{NO}_{3}\right)_{2}$ & 100 & $96 \pm 1$ \\
\hline $\mathrm{Al}^{3+}$ & $\mathrm{Al}\left(\mathrm{NO}_{3}\right)_{3} .9 \mathrm{H}_{2} \mathrm{O}$ & 50 & $95 \pm 2$ \\
\hline $\mathrm{Cl}^{-}$ & $\mathrm{NaCl}$ & 1000 & $98 \pm 3$ \\
\hline $\mathrm{PO}_{4}^{3-}$ & $\mathrm{Na}_{3} \mathrm{PO}_{4}$ & 1000 & $100 \pm 2$ \\
\hline $\mathrm{SO}_{4}{ }^{2-}$ & $\mathrm{Na}_{2} \mathrm{SO}_{4}$ & 100 & $99 \pm 4$ \\
\hline $\mathrm{NO}_{3}^{-}$ & $\mathrm{NaNO}_{3}$ & 1000 & $97 \pm 3$ \\
\hline
\end{tabular}

\section{Real sample applications}

This VA-IL-DLLME method was applied to determine RhB contents of different samples including anti-freezes, liquid soap, lipsticks, matches and red pencil core. The standard addition technique was also used for the determination of real samples by adding $0.125 \mu \mathrm{g}$ and $0.250 \mu \mathrm{g}$ of RhB. First, RhB amount of each aqueous solution belonging the real samples including anti-freezes, liquid soap, lipsticks, matches and 


\begin{tabular}{lr}
\hline Abdullah Taner BİŞGIN & $10(3): 1820-1832,2020$ \\
\hline Vortex-assisted ionic liquid-based dispersive liquid-liquid micro-extraction and spectrofluorometric determination of Rhodamine \\
B in anti-freeze, lipstick, liquid soap, matches and red pencil core
\end{tabular}

red pencil core were determined. Then, $0.125 \mu \mathrm{g}$ and $0.250 \mu \mathrm{g}$ of $\mathrm{RhB}$ dyes were separately added to the each of same solutions of the real samples. Finally, the solutions were subjected to developed method. Recovery results and RhB contents of the analyzed samples are given in Table 2 with standard deviations. Calculated recovery results with using standard addition technique were between \% 96 and \% 101. RhB concentrations of anti-freezes, liquid soap, lipsticks, matches and red pencil were separately determined and calculated for each samples according to applied pretreatment procedures and necessary dilutions which were given in "Pretreatment of real samples" part. RhB contents of liquid and solid samples were determined between $2.05 \mu \mathrm{g} \mathrm{mL}^{-1}$ and $10.05 \mu \mathrm{g} \mathrm{mL}^{-1}$ and $307 \mu \mathrm{g} \mathrm{g}^{-1}$ and $2.75 \mathrm{mg} \mathrm{g}^{-1}$, respectively. The accuracy of the method with satisfactory quantitative results indicated the applicability of the method for determination of $\mathrm{RhB}$ in different matrix samples.

Table 2. Recoveries and RhB contents of real samples with standard addition technique, $\mathrm{N}=4$

\begin{tabular}{lllll}
\hline Sample & RhB added $(\boldsymbol{\mu g})$ & RhB found $(\boldsymbol{\mu g})$ & \% Recovery & RhB content \\
Anti-freeze 1 & - & ${ }^{\mathrm{a}} 0.112 \pm 0.005$ & - & \\
& 0.125 & $0.233 \pm 0.011$ & $98 \pm 4$ & $6.52 \pm 0.05\left(\mu \mathrm{g} \mathrm{mL}^{-1}\right)$ \\
Anti-freeze 2 & 0.250 & $0.359 \pm 0.018$ & $99 \pm 3$ & \\
& - & $0.165 \pm 0.007$ & - & \\
& 0.125 & $0.279 \pm 0.014$ & $96 \pm 4$ & $10.05 \pm 0.12\left(\mu \mathrm{g} \mathrm{mL}^{-1}\right)$ \\
Liquid soap & 0.250 & $0.411 \pm 0.019$ & $99 \pm 3$ & \\
& - & $0.202 \pm 0.008$ & - & \\
& 0.125 & $0.318 \pm 0.012$ & $97 \pm 3$ & $2.05 \pm 0.04\left(\mu \mathrm{g} \mathrm{mL}^{-1}\right)$ \\
Lipstick 1 & 0.250 & $0.443 \pm 0.017$ & $98 \pm 4$ & \\
& - & $0.245 \pm 0.009$ & - & $465 \pm 15\left(\mu \mathrm{g} \mathrm{g}^{-1}\right)$ \\
Lipstick 2 & 0.125 & $0.368 \pm 0.013$ & $99 \pm 2$ & \\
& 0.250 & $0.485 \pm 0.023$ & $98 \pm 4$ & $307 \pm 11\left(\mu \mathrm{g} \mathrm{g}^{-1}\right)$ \\
Matches & - & $0.230 \pm 0.010$ & - & \\
& 0.125 & $0.345 \pm 0.016$ & $97 \pm 2$ & $1.07 \pm 0.06\left(\mathrm{mg} \mathrm{g}^{-1}\right)$ \\
Red pencil core & 0.250 & $0.461 \pm 0.021$ & $96 \pm 3$ & \\
& - & $0.175 \pm 0.007$ & - & \\
& 0.125 & $0.289 \pm 0.011$ & $96 \pm 4$ & $2.75 \pm 0.03\left(\mathrm{mg} \mathrm{g}^{-1}\right)$ \\
\hline${ }^{a}$ Mean \pm standard deviation & $0.421 \pm 0.014$ & $99 \pm 3$ & \\
\hline
\end{tabular}

\section{Analytical characteristics of the method}

Analytic specifications of the proposed method were investigated. Limit of detection (LOD) of the method was determined as $0.01 \mu \mathrm{g} \mathrm{L}^{-1}$ for $\mathrm{RhB}$ dye. LOD was calculated according to (BT+3SD/m)/PF where BT is average of 21 blank solutions, SD is standard deviation of 21 blank solutions, $\mathrm{m}$ is slope of the calibration curve and PF is preconcentration factor. Linear dynamic range (LDR) was obtained at the concentration range between $0.025 \mu \mathrm{g} \mathrm{L}^{-1}$ and $1000 \mu \mathrm{g} \mathrm{\textrm {L } ^ { - 1 }}$ with $\mathrm{A}=631.06 \mathrm{C}-0.0083$ equation and $\mathrm{R}^{2}=0.9998$ correlation coefficient. In the equation, $\mathrm{A}$ and $\mathrm{C}$ are absorbance unit and $\mathrm{RhB}$ concentration, respectively. Preconcentration factor was obtained as 30. Relative standard deviations (\%RSD) was obtained as \%3.9 for the ten replicates measurements of $0.125 \mu \mathrm{g} \mathrm{L}^{-1}$ Rhodamine B. The method analytical characteristics were comparatively given in Table 3. 
Table 3. Comparison of the method analytical features with recent reported studies

\begin{tabular}{|c|c|c|c|c|c|c|c|}
\hline Method & Instrument & Sample & $\begin{array}{c}\text { LOD } \\
\left(\mu g L^{-1}\right)\end{array}$ & $\begin{array}{c}\mathbf{L D R} \\
\left(\mu \mathrm{g} \mathrm{L}^{-1}\right)\end{array}$ & $\begin{array}{l}\text { RSD } \\
(\%)\end{array}$ & $\mathbf{P F}$ & Reference \\
\hline SPE & UV-Vis & $\begin{array}{l}\text { Matches tips, water, dish } \\
\text { washing liquid }\end{array}$ & 3.94 & $20-300$ & 1.16 & 26 & Nekoeinia et al., 2016 \\
\hline SPE & Fluorescence & $\begin{array}{l}\text { Matches tips, shampoo, eye } \\
\text { shadow, pencil lead }\end{array}$ & 0.1 & $0.35-5.00$ & 8.2 & 33 & Bagheri et al., 2013 \\
\hline CPE & UV-Vis & $\begin{array}{l}\text { Lipstick, water, anti-freeze, } \\
\text { waste-water }\end{array}$ & 0.70 & $50-5000$ & 5.0 & 40 & Bişgin et al., 2018 \\
\hline DLLME & UV-Vis & $\begin{array}{l}\text { Black tea, red wine, chili } \\
\text { powder }\end{array}$ & 1.48 & $5-450$ & 4.7 & 20 & Xiao et al., 2014 \\
\hline $\mathrm{CPE}$ & UV-Vis & Tap water, waste-water & 0.04 & $30-300$ & 6.75 & 28 & $\begin{array}{l}\text { Ghasemi and } \\
\text { Kaykhaii, } 2016\end{array}$ \\
\hline $\begin{array}{l}\text { DES- } \\
\text { LPME }\end{array}$ & UV-Vis & $\begin{array}{l}\text { Lipstick, cologne, river water, } \\
\text { nail polish cleaner }\end{array}$ & 2.2 & - & 2.3 & 25 & $\begin{array}{l}\text { Yilmaz and Soylak, } \\
2018\end{array}$ \\
\hline CPE & UV-Vis & Soap, soft pastel, matches tips & 1.3 & $5-550$ & 2.40 & 8.5 & Pourreza et al., 2008 \\
\hline $\begin{array}{l}\text { VA-IL- } \\
\text { DLLME }\end{array}$ & Fluorescence & $\begin{array}{l}\text { Lipstick, soap, anti-freeze, red } \\
\text { pencil core, matches }\end{array}$ & 0.01 & $\begin{array}{c}0.025- \\
1000\end{array}$ & 3.9 & 30 & Present work \\
\hline SPE: & \multicolumn{7}{|c|}{ Solid-phase extraction } \\
\hline CPE & \multicolumn{7}{|c|}{ Cloud point extraction } \\
\hline DLLME: & \multicolumn{7}{|c|}{ Dispersive liquid-liquid micro-extraction } \\
\hline $\begin{array}{l}\text { DES- } \\
\text { LPME: }\end{array}$ & \multicolumn{7}{|c|}{ Deep eutectic solvent liquid phase micro-extraction } \\
\hline $\begin{array}{l}\text { VA-IL- } \\
\text { DLLME }\end{array}$ & \multicolumn{7}{|c|}{$\begin{array}{l}\text { Vortex assisted ionic liquid-based dispersive liquid-liquid } \\
\text { micro-extraction }\end{array}$} \\
\hline
\end{tabular}

\section{CONCLUSIONS}

In the present proposed study, VA-IL-DLLME method was developed for extraction and spectrofluorometric determination of RhB in real samples. VA-IL-DLLME offers high extraction efficiency within a short time. The developed method is fast, simple inexpensive and uses very little amounts of toxic organic solvents when compared with other preconcentration methods such as SPE. Obtained quantitative satisfactory recovery results with analyte addition technique proved the applicability of the method to real liquid and solid samples including lipsticks, matches, anti-freezes, red pencil core and liquid soap. Moreover, present method determines the RhB concentrations of samples without applying centrifuge. At the optimum conditions of the developed method, ionic liquid $\left[\mathrm{C}_{4} \mathrm{MIM}\right]\left[\mathrm{PF}_{6}\right]$ extracted only $\mathrm{RhB}$ molecules as quantitative from aqueous sample solution in presence of other matrix dyes given in Table 1. This circumstance has provided the selectivity to the proposed method. Because of fluorescence feature of RhB and usage of spectrofluorometer in determination step, LOD value of the method was determined as too low because fluorescence detection is very sensitive and RhB has considerably high molar absorptivity coefficient. Moreover, excitation wavelengths and emission wavelengths are specific for each dye that has fluorescence characteristic. In addition, fluorescence determination provided selectivity to the developed method because RhB has the fluorescence characteristic among other matrix dyes that are given in Table 1. The used dyes in matrix study have not fluorescence characteristics therefore, any emission wavelengths, which could be interfered the fluorescence determination, were not observed by fluorescence excitation with using fluorescence spectrometer. Thus, only RhB molecules were determined applying both excitation and emission wavelength. In addition, differences between excitation and emission wavelength of RhB increased the selectivity. 


\section{REFERENCES}

Alesso M, Bondioli G, Talío MC, Luconi MO, Fernández LP, 2012. Micelles mediated separation fluorimetric methodology for Rhodamine B determination in condiments, snacks and candies. Food Chemistry, 134: 513-517.

Altunay N, Elik A, Gürkan R, 2019. Monitoring of some trace metals in honeys by flame atomic absorption spectrometry after ultrasound assisted-dispersive liquid liquid microextraction using natural deep eutectic solvent. Microchemical Journal, 147: 49-59.

Bagheri H, Daliri R, Roostaie A, 2013. A novel magnetic poly(aniline-naphthylamine)-based nanocomposite for micro solid phase extraction of rhodamine B. Analytica Chimica Acta, 794: 3846.

Bağda E, Tüzen M, 2017. A simple and sensitive vortex-assisted ionic liquid-dispersive microextraction and spectrophotometric determination of selenium in food samples Food Chemistry, 232: 98-104.

Bakheet AAA, Zhu XS, 2017. Determination of Rhodamine B in Food Samples by Fe3O4@ Ionic Liquids$\beta$-Cyclodextrin Cross Linked Polymer Solid Phase Extraction Coupled with Fluorescence Spectrophotometry. Journal of Fluorescence, 27: 1087-1094.

Bişgin AT, 2018. Simultaneous Preconcentration and Determination of Brilliant Blue and Sunset Yellow in Foodstuffs by Solid-Phase Extraction Combined UV-Vis Spectrophotometry. Journal of AOAC International, 101: 1850-1856.

Bişgin AT, Sürme Y, Uçan M, Narin İ, 2018. Separation, Preconcentration and Spectrophotometric Determination of Rhodamine B in Industrial, Cosmetic and Water Samples by Cloud Point and Solid Phase Extraction. Journal of Analytical Chemistry, 73: 452-458.

Bişgin AT, 2019a. Simultaneous Extraction and Determination of Allura Red (E129) and Brilliant Blue FCF (E133) in Foodstuffs by Column Solid-Phase Spectrophotometry. Journal of AOAC International, 102: 181-188.

Bişgin AT, 2019b. Surfactant-Assisted Emulsification and Surfactant-Based Dispersive Liquid-Liquid Microextraction Method for Determination of $\mathrm{Cu}$ (II) in Food and Water Samples by Flame Atomic Absorption Spectrometry. Journal of AOAC International, 102: 1516-1522.

Chen D, Zhao Y, Miao H, Wu Y, 2014. A novel cation exchange polymer as a reversed-dispersive solid phase extraction sorbent for the rapid determination of rhodamine B residue in chili powder and chili oil. Journal of Chromatography A, 1374: 268-272.

Chen J, Zhu X, 2016. Magnetic solid phase extraction using ionic liquid-coated core-shell magnetic nanoparticles followed by high-performance liquid chromatography for determination of Rhodamine B in food samples. Food Chemistry, 200: 10-15.

Cheng YY, Tsai TH, 2016. A validated LC-MS/MS determination method for the illegal foodadditive rhodamine B: Applications of a pharmacokinetic study in rats. Journal of Pharmaceutical and Biomedical Analysis, 125: 394-399.

Elik A, Altunay N, Gürkan R, 2017. Microextraction and preconcentration of Mn and Cd from vegetables, grains and nuts prior to their determination by flame atomic absorption spectrometry using room temperature ionic liquid. Journal of Molecular Liquids, 247: 262-268. 
Fu DS, Wu PP, Zhong XD, Liu Q, Luo HD, Li YQ, 2015. A Simple Synchronous Fluorescence Approach for Rapid and Sensitive Determination of Rhodamine B in Chilli Products. Food Analytical Methods, 8: 189-194.

Ghasemi E, Kaykhaii M, 2016. Application of Micro-cloud point extraction for spectrophotometric determination of Malachite green, Crystal violet and Rhodamine B in aqueous samples. Spectrochimica Acta A, 164: 93-97.

Li J, Ding XM, Liu DD, Guo F, Chen Y, Zhang YB, Liu HM, 2013. Simultaneous determination of eight illegal dyes in chili products by liquid chromatography-tandem mass spectrometry. Journal of Chromatography B, 942-943: 46-52.

Li L, Chen W, Li H, Iqba J, Zhu Y, Wu T, Du Y, 2020. Rapid determination of fumonisin (FB1) by syringe SPE coupled with solid-phase fluorescence spectrometry. Spectrochimica Acta A, 226: 117549 1-6.

Liang F, Jin D, Ma P, Wang D, Yang Q, Song D, Wang X, 2015. Rapid Determination of Rhodamine B in Chili Powder by Surface-Enhanced Raman Spectroscopy. Analytical Letters, 48:1918-1929.

Liu X, Zhang X, Zhou Q, Bai B, Ji S, 2013. Spectrometric Determination of Rhodamine B in Chili Powder After Molecularly Imprinted Solid Phase Extraction. Bulletin of the Korean Chemical Society, 34 : 3381-3386.

Nekoeinia M, Dehkordi MK, Kolahdoozan M, Yousefinejad S, 2016. Preparation of epoxidized soybean oil-grafted $\mathrm{Fe}_{3} \mathrm{O}_{4}-\mathrm{SiO}_{2}$ as a water-dispersible hydrophobic nanocomposite for solid-phase extraction of rhodamine B. Microchemical Journal, 129: 236-242.

Pourreza N, Rastegarzadeh S, Larki A, 2008. Micelle-mediated cloud point extraction and spectrophotometric determination of rhodamine B using Triton X-100. Talanta, 77: 733-736.

Qi P, Lin Z, Li J, Wang CL, Meng WW, Hong H, Zhang X, 2014. Development of a rapid, simple and sensitive HPLC-FLD method for determination of rhodamine B in chili-containing products. Food Chemistry, 164: 98-103.

Ranjbari E, Hadjmohammadi MR, 2015. Optimization of magnetic stirring assisted dispersive liquid-liquid microextraction of rhodamine $\mathrm{B}$ and rhodamine $6 \mathrm{G}$ by response surface methodology: Application in water samples, soft drink, and cosmetic products. Talanta, 139: 216-225.

Roostaie A, Allahnoori F, Ehteshami S, 2017. Composite Magnetic Nanoparticles (CuFe2O4) as a New Microsorbent for Extraction of Rhodamine B from Water Samples. Journal of AOAC International, 100: 1539-1543.

Sadeghi M, Shiri F, Kordestani D, Mohammadi P, Alizadeh A, 2018. SBA-15/Metformin as a novel sorbent combined with surfactant-assisted dispersive liquid-liquid microextraction (SA-DLLME) for highly sensitive determination of $\mathrm{Pb}, \mathrm{Cd}$ and $\mathrm{Ni}$ in food and environmental samples. Journal of Iranian Chemical Society, 15: 753-768.

Soylak M, Unsal YE, Yilmaz E, Tuzen M, 2011. Determination of rhodamine B in soft drink, waste water and lipstick samples after solid phase extraction. Food and Chemical Toxicology, 49: 1796-1799.

Su X, Li X, Li J, Liu M, Lei F, Tan X, Li P, Luo W, 2015. Synthesis and characterization of core-shell magnetic molecularly imprinted polymers for solid-phase extraction and determination of Rhodamine B in food. Food Chemistry, 171: 292-297.

Sun D, Yang X, 2017. Rapid Determination of Toxic Rhodamine B in Food Samples Using Exfoliated Graphene-Modified Electrode. Food Analytical Methods, 10: 2046-2052. 
Tatebe C, Zhong X, Ohtsuki T, Kubota H, Sato K, Akiyama H, 2014. A simple and rapid chromatographic method to determine unauthorized basic colorants (rhodamine B, auramine $\mathrm{O}$, and pararosaniline) in processed foods. Food Science and Nutrition, 2: 547-556.

Unsal YE, Soylak M, Tuzen M, 2014a. Dispersive liquid-liquid microextraction-spectrophotometry combination for determination of rhodamine B in food, water, and environmental samples. Desalination and Water Treatment, 55: 2103-2108.

Unsal YE, Soylak M, Tuzen M, 2014b. Spectrophotometric Detection of Rhodamine B after SeparationEnrichment by Using Multi-walled Carbon Nanotubes. Journal of AOAC International, 97: 14591462.

Wang W, Du Y, Xiao Z, Li Y, Li B, Yang G, 2017. Determination of Trace Rhodamine B in Chili Oil by Deep Eutectic Solvent Extraction and an Ultra High-Performance Liquid Chromatograph Equipped with a Fluorescence Detector. Analytical Science, 33: 715-717.

Xiao N, Deng J, Huang K, Ju S, Hu C, Liang J, 2014. Application of derivative and derivative ratio spectrophotometry to simultaneous trace determination of rhodamine B and Rhodamine $6 \mathrm{G}$ after dispersive liquid-liquid microextraction. Spectrochimica Acta A, 128: 312-318.

Xu X, Zhang M, Wang L, Zhang S, Liu M, Long N, Qi X, Cui Z, Zhang L, 2016. Determination of Rhodamine B in Food Using Ionic Liquid-Coated Multiwalled Carbon Nanotube-Based UltrasoundAssisted Dispersive Solid-Phase Microextraction Followed by High-Performance Liquid Chromatography. Food Analytical Methods, 9: 1696-1705.

Yan J, Cen JM, Tan XC, Tan SF, Wu YY, Zhang H, Wang Q, 2017. Determination of trace rhodamine B by spectrofluorometry and magnetic solid phase extraction based on a $3 \mathrm{D}$ reduced graphene oxide composite. Analytical Methods, 9: 5433-5440.

Yilmaz E, Soylak M, 2018. A novel and simple deep eutectic solvent based liquid phase microextraction method for rhodamine B in cosmetic products and water samples prior to its spectrophotometric determination. Spectrochimica Acta A, 202: 81-86. 